\title{
Words without Vowels: Phonetic and Phonological Evidence from Tashlhiyt Berber ${ }^{1}$
}

\begin{abstract}
Rachid Ridouane
UPRESA 7018 CNRS-Université Paris 3

Abstract

This article deals with the Tashlhiyt dialect of Berber (henceforth TB) spoken in the southern part of Morocco. In TB, words may consist entirely of consonants without vowels and sometimes of only voiceless obstruents, e.g. tft $\chi$ tstt "you rolled it (fem)". In this study we have carried out acoustic, video-endoscopic and phonological analyses to answer the following question: is schwa, which may function as syllabic, a segment at the level of phonetic representations in TB? Video-endoscopic films were made of one male native speaker of TB, producing a list of forms consisting entirely of voiceless obstruents. The same list was produced by 7 male native speakers of TB for the acoustic analysis. The phonological analysis is based on the behaviour of vowels with respect to the phonological rule of assibilation. This study shows the absence of schwa vowels in forms consisting of voiceless obstruents.
\end{abstract}

\section{Introduction}

Berber is spoken in large parts of North Africa and especially in Morocco and Algeria. Berber is not a standard or a codified language; it exists only through its dialectal or regional realizations. Tashlhiyt Berber (henceforth TB), which is spoken in the Southern part of Morocco, is a homogeneous dialect which enables all the Chleuhs to communicate without difficulties. This apparent homogeneity, however, conceals a certain amount of heterogeneity. Following the work of Boukous (1994), TB may be subdivided into three subsystems :

- The occlusive subsystem spoken in Agadir and its suburbs. It is considered to be the "received Tashlhiyt pronunciation".

- The fricative subsystem spoken in Haha which spirantizes the non coronal obstruents /b, k, g/.

- The sibilant subsystem spoken in the Anti-Atlas mountains where /t/ and /d/ are realized as [s] and [z] respectively. $^{2}$

At the phonological level, TB varieties share the same phonological system founded upon the same correlations. The vowels of TB are /a, i, u/. In this article, all transcriptions not enclosed between slanted lines are phonetic representations given in a broad transcription. The phonetic transcription of a form is meant to represent its pronunciation in isolation. The schwa vowel, which is the main topic of this paper, is transcribed as [e]. Complex consonant clusters are a common occurrence in all the varieties of TB at the underlying level as well as at the phonetic one. Indeed, widely attested forms may consist entirely of consonants without vowels and sometimes of only voiceless consonants, e.g. tqssf "it shrunk (fem)", tfktstt "you gave it (fem)". How should these words be syllabified and, being deprived of full vowels, sonorants and even of voiced obstruents, which segments may function as syllabic?

\footnotetext{
${ }^{1}$ I am grateful to A. Rialland, F. Dell, N. Clements and J. Vaissière for discussions and comments on an earlier version of this paper. I am also grateful to Dr. Lise Crevier for her comments and assistance for collecting fiberscopic data at Laenec Hospital, Paris. I would also like to thank B. Gautheron and C. Zeroual for technical assistance and all the subjects for their kind participation in this study. Errors are ours only.

${ }^{2}$ Each subsystem is represented in this paper by the area where it is spoken: Agadir for the occlusive, Haha for the spirant and Anti-Atlas for the sibilant.
} 
These questions have aroused much interest among phonologists and phoneticians (Elmedlaoui, 1985, Dell and Elmedlaoui, 1985, 1988, 1996a-b, 1997; Louali and Puech, 1996, 1999a., 1999b.; Boukous, 1990; Coleman, 1996, 1999; Clements, 1997). Dell and Elmedlaoui claim that surface syllables may consist only of consonants with $\mathrm{CC}$ and $\mathrm{CCC}$ (where the second $\mathrm{C}$ is the nucleus) existing along side the conventional syllable types $\mathrm{CV}$ and $\mathrm{CVC}$. The syllable organization is determined on the basis of local relations in sonority. According to Dell and Elmedlaoui, there exist ultra short vowels but they occur only adjacent to voiced consonants. No voiced vocoid, however short it is, can be heard in sequences of voiceless obstruents. Dell and Elmedlaoui's data are based on the variety of Tashlhiyt spoken in Imdlawen valley.

Coleman (1996, 1999) argues for a different claim. According to him, epenthetic vowels exist in TB and they are the phonetic realizations of syllable nuclei. Where no vowel epenthetic is evident, it can be regarded as hidden by the following consonant. In the framework of the co-production model, Coleman interprets the syllabic consonants as the coproduced realization of phonological vowel and consonant. Coleman's analysis is based on published material and on his own work on the variety of TB spoken in Agadir (Coleman 1996) and the variety of TB spoken in Imdlawen valley (Coleman 1999).

Louali and Puech, basing their arguments on some acoustic and perceptual analyses, conclude that a vocoid is always present in the realization of a TB word, if not a full vowel then a schwa vocoid, even within words composed only of unvoiced obstruents. Louali and Puech's analyses are based on their own work on different varieties of TB.

\subsection{Aim}

If, as Dell and Elmedlaoui claim, schwa is only an aspect of the realization of a voiced consonant, and not a segment, then one should not find schwa and voicing or any vocalic gesture in a word consisting of voiceless obstruents. We don't know of a mechanism that would introduce voicing in a sequence deprived of [+ voiced] segments. On the other hand, if these words contain schwas, then that would mean that the phonetic representation of TB contains at least four vowels: the realizations of /a, i, u/ and one segment schwa which can thus occupy the nucleus of a syllable. We have investigated the three varieties of TB. Our focus in this paper is the following: to what extent can we speak of voiceless obstruents as being syllabic nuclei? One way of answering this question is to determine if schwa is a segment at the level of phonetic representations of TB. We will examine through spectrography and video-endoscopy the presence or the absence of voicing or vowel gestures in sequences of voiceless obstruent clusters. A phonological argumentation will also be developed. 


\section{Spectrographic analysis}

\subsection{Method}

For the spectrographic analysis, the 23 forms listed in (1), consisting of widely attested verbs in TB, were produced by 7 male adult TB native speakers. These verbs only contain voiceless sequences:

Sequences of two voiceless obstruents :

$$
\begin{array}{ll}
\mathrm{ks} & \text { "feed on" } \\
\mathrm{fk} & \text { "give" }
\end{array}
$$

Sequences of three voiceless obstruents:

$\begin{array}{ll}\mathrm{kst} & \text { "feed it on" } \\ \mathrm{kt} & \text { "give it" } \\ \mathrm{kks} & \text { "fake off" } \\ \mathrm{s} \chi \mathrm{f} & \text { "operate" away" } \\ \mathrm{fth} & \end{array}$

Sequences of four voiceless obstruents :

$\begin{array}{ll}\text { tfth } & \text { "she operated" } \\ \text { tkSf } & \text { "it is dirty" } \\ \text { tfss } & \text { "she is quiet" } \\ \text { fqqs } & \text { "irritate" }\end{array}$

Sequences of five voiceless obstruents :

$\begin{array}{ll}\mathrm{t} f \mathrm{tft} & \text { "you crushed" } \\ \mathrm{tkkst} & \text { "you took off" } \\ ! \mathrm{t} \chi \mathrm{tft} & \text { "you stole" } \\ \mathrm{kkstt} & \text { "take it off (fem)" } \\ \mathrm{tfs} \chi \mathrm{t} & \text { "you cancelled" } \\ \mathrm{tqssf} & \text { "it shrunk (fem)" }\end{array}$

Sequences of six voiceless obstruents and more:

$\begin{array}{ll}\text { sfqqst } & \text { "irritate him" } \\ \text { tfktstt } & \text { "you gave it" } \\ \text { tsskfft } & \text { "you made it dirty" } \\ \text { tkkststt } & \text { "you took it off (fem)" } \\ \text { tftktstt } & \text { "you sprained it (fem)" } \\ \text { tft } \text { tstt } & \text { "you rolled it (fem)" }\end{array}$

We have taken into consideration the different varieties of $\mathrm{TB}$ and chosen our subjects according to their native TB subsystem. This breakdown is illustrated in Table 1 below:

Table 1. The breakdown of the subjects according to their native TB subsystem :

\begin{tabular}{|c|c|c|}
\hline Subject & Subsystem & Age \\
\hline E & Agadir & 31 \\
\hline H & Agadir & 26 \\
\hline S & Anti-Atlas & 33 \\
\hline B & Anti-Atlas & 30 \\
\hline K & Haha & 63 \\
\hline A & Haha & 28 \\
\hline R & Haha & 30 \\
\hline
\end{tabular}

\footnotetext{
3 “"” indicates that all the segments of the word are dorsopharyngealized.
} 
Each subject produced each form in (1) at least three times. Only the first three utterances of each form were analysed using Unice software. We looked into the acoustic realizations of the items (1) to determine the presence or the absence of schwa vowels.

\subsection{Results and discussion}

A first result of our spectrographic data shows the predominance of the realizations of forms (1) with no voiced vocoids. Only 68 out of 465 utterances are realized with schwa vowels. Table 2 below summarizes these different realizations for each subject.

Table 2. The realizations of schwa vowel in the utterances of 7 subjects.

\begin{tabular}{|c|c|c|c|c|c|c|c|c|}
\hline & \multicolumn{2}{|c|}{ Agadir } & \multicolumn{2}{|c|}{ AA } & \multicolumn{3}{|c|}{ Haha } & \\
\hline & $E$ & $H$ & $S$ & $B$ & $K$ & $A$ & $R$ & TOTAL \\
\hline $\mathrm{Fk}$ & 3 & 3 & 0 & 0 & 0 & 0 & 0 & $6 / 21$ \\
\hline $\mathrm{Ks}$ & 3 & 3 & 0 & 0 & 0 & 0 & 0 & $6 / 21$ \\
\hline Fkt & 3 & 3 & 0 & 0 & 0 & 0 & 0 & $6 / 21$ \\
\hline Kst & 3 & 3 & 0 & 0 & 0 & 0 & 0 & $6 / 21$ \\
\hline Fth & 3 & 0 & 0 & 0 & 0 & 0 & 0 & $3 / 21$ \\
\hline Kks & 2 & 0 & 0 & 0 & 0 & 0 & 0 & $2 / 21$ \\
\hline$s \chi f$ & 3 & 0 & 0 & 0 & 0 & 0 & 0 & $3 / 21$ \\
\hline Fqqs & 0 & 0 & 0 & 0 & 0 & 0 & 0 & $0 / 21$ \\
\hline Tfss & 3 & 0 & 0 & 0 & 0 & 0 & 0 & $3 / 21$ \\
\hline Tfth & 3 & 0 & 0 & 0 & 0 & 0 & 0 & $3 / 21$ \\
\hline tk $\int f$ & 3 & 0 & 1 & 0 & 0 & 0 & 0 & $4 / 21$ \\
\hline Tkkst & 3 & 0 & 0 & 0 & 0 & 0 & 0 & $3 / 21$ \\
\hline Kkstt & 3 & 0 & 0 & 0 & 0 & 0 & 0 & $3 / 21$ \\
\hline $\mathrm{tfs} \chi \mathrm{t}$ & 3 & 0 & 0 & 0 & 0 & 0 & 0 & $3 / 21$ \\
\hline $\mathrm{t} \mathrm{t} \mathrm{ft}$ & 3 & 0 & 0 & 0 & 0 & 0 & 0 & $3 / 21$ \\
\hline Tqssf & 3 & 0 & 0 & 0 & 0 & 0 & 0 & $3 / 21$ \\
\hline$! \mathrm{t} \chi \mathrm{tft}$ & 3 & 0 & 0 & 0 & 0 & 0 & 0 & $3 / 21$ \\
\hline sfqqst & 3 & 0 & 0 & 1 & 0 & 0 & 0 & $4 / 21$ \\
\hline tsskfft & 3 & 0 & 0 & 0 & 0 & 0 & 0 & $3 / 21$ \\
\hline Tfktstt & 1 & $--^{4}$ & 0 & 0 & 0 & 0 & 0 & 1/18 \\
\hline tftktstt & - & - & 0 & 0 & 0 & 0 & 0 & $0 / 15$ \\
\hline $\mathrm{tft} \chi \mathrm{tstt}$ & 0 & - & 0 & 0 & 0 & 0 & 0 & 0/18 \\
\hline tkkststt & - & - & 0 & 0 & 0 & 0 & 0 & $0 / 15$ \\
\hline
\end{tabular}

The number of the realizations with a voiced vocoid is indicated in the relevant box. Subject $\mathrm{B}$, for instance, did not pronounce any schwa during his three realizations of the form $f k(0)$, whereas subject $E$ realised the same form with a schwa during his three utterances (3).

The three subjects of Haha ( $\mathrm{K}, \mathrm{A}$ and $\mathrm{R})$ never pronounced schwas within sequences of voiceless obstruents. For the Anti-Atlas (AA) subjects only two utterances contained schwas at the final position in the realizations of: tkffe for $\mathrm{S}$ and sfqqste for B. By contrast, voiced vocoids are widely attested in the realizations of Agadir subjects: $\mathrm{H}$ and especially $\mathrm{E}$. How should we explain this variation? Do these differences reflect a difference in the syllabic

\footnotetext{
${ }^{4}$ This symbol means that the subject considers his three utterances to be incorrect.
} 
structure between the different TB subsystems? Or do they reflect only individual variation? Before answering these questions, let us determine the distribution of these schwas in the realizations of $\mathrm{E}$ and $\mathrm{H}$. Table 3 below sums up these distributions :

Table 3. The distribution of schwa vowels in the realizations of subjects $\mathrm{E}$ and $\mathrm{H}$.

\begin{tabular}{|c|c|c|}
\hline & $E$ & $H$ \\
\hline $\mathrm{Fk}$ & Fke & fke \\
\hline Ks & Kse & kse \\
\hline Fkt & Fkte & fkte \\
\hline Kst & Kste & kste \\
\hline Fth & fthe & --- \\
\hline Kks & kkse $2 / 3$ & --- \\
\hline$s \chi f$ & sqef & --- \\
\hline tfss & tfess & --- \\
\hline Tfth & $\begin{array}{c}1 / 3 \text { tfteђ } ; 2 / 3 \\
\text { tfthe }\end{array}$ & --- \\
\hline tk $\int f$ & tk $\int \mathrm{fe}$ & --- \\
\hline tkkst & tkkste & --- \\
\hline kkstt & kkste & --- \\
\hline $\mathrm{Tfs} \chi \mathrm{t}$ & tfs $\chi$ te & --- \\
\hline $\mathrm{t} \int \mathrm{tft}$ & $\mathrm{t} \int \mathrm{tfte}$ & --- \\
\hline tqssf & tqssfe & --- \\
\hline$! \mathrm{t} \chi \mathrm{tft}$ & !t $\chi$ tfte & --- \\
\hline sfqqst & $\begin{array}{l}\text { 1/3 sfeqqst } \\
2 / 3 \text { sfqqste }\end{array}$ & --- \\
\hline tssk $\int \mathrm{ft}$ & tsskffte & --- \\
\hline tfktstt & tfktstte $1 / 3$ & - \\
\hline
\end{tabular}

Some important observations may be made from the data which we have presented so far. Firstly, the voiced vocoid is mainly attested at the end of the utterances. Subject $\mathrm{H}$ realizes all his schwas at this position. Schwa is attested at the medial position in only four items for subject E. Consider below, the spectrogram of the form $f k e$ as realized by $\mathrm{H}$ :

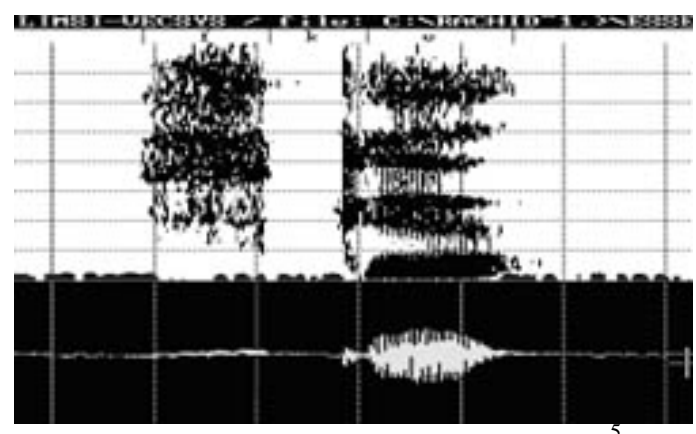

Figure 1. A spectrogram of $f k$ «give ! ${\text { par } \mathrm{H}^{5}}^{5}$

\footnotetext{
${ }^{5}$ The horizontal grid lines in all the spectrograms mark divisions into KHz.
} 
The presence of a schwa vowel in this form was also observed by Louali and Puech (1999a, Figure 2) "Figure 2 manifests the presence of a schwa vowel after the release of the stop, which then occupies the syllabic position." (p. 39). Louali and Puech added that: "No vocoid is attested in the spectrogram in Figure 3 [for their form $f k t$ ] where the stop also occupies the syllabic position" (ibid). The fact that schwa is present in one form and absent in the other is not due to the syllabicity of the velar but to the final position the segment occupies. The velar stop is followed by a schwa vowel in Louali and Puech's Figure 2 because it occupies the final position, a position which it no longer occupies in their form fkt. One should wonder why schwa is absent not after $/ \mathrm{k} /$ but rather after the final $/ \mathrm{t} /$. We will show below that this may be adequately accounted for by the fact that this segment is very unstable. The presence of schwa vowels at the end of some utterances ${ }^{7}$, especially after a stop, is attested in other languages. This is the case for instance of some French words (cap, bec etc.). The presence of this schwa aids the hearer to identify the final consonant, occurring in a naturally weak position, by placing it in a prevocalic position where cues to its place of articulation (burst, noise transient, formant transitions) will be present. ${ }^{8}$

A second important observation is that the distribution of schwas may be particularly unstable even within one same subject. Consider for instance the two utterances of the form sfqqst as realized by $\mathrm{E}$ in a period of less than three seconds. As is shown in the Figure 2, a voiced vocoid is realized between /f/ and /q/ in the first utterance but word finally in the second. Not all the forms realized by E contain schwas. He may realize long voiceless sequences with no vowel at all. This is the case for instance for the items fqqs, tfktstt and tft $\chi$ tstt. Below in Figure 3 we see a spectrogram of a sequence of 8 voiceless obstruents realized by E with no schwa vowel.

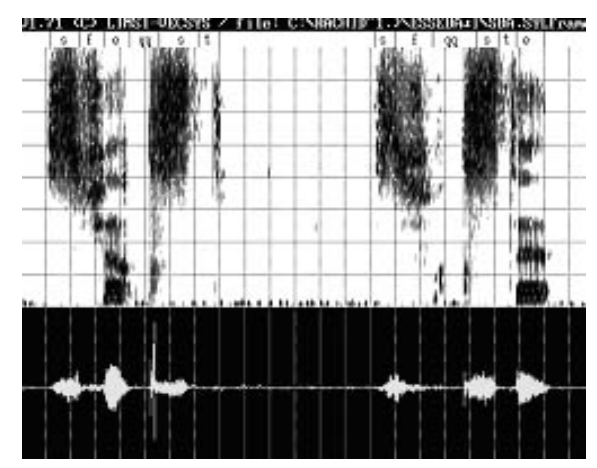

Figure 2. A Spectrogram of two pronunciations of $s f q q s t$ « irritate him» by E .

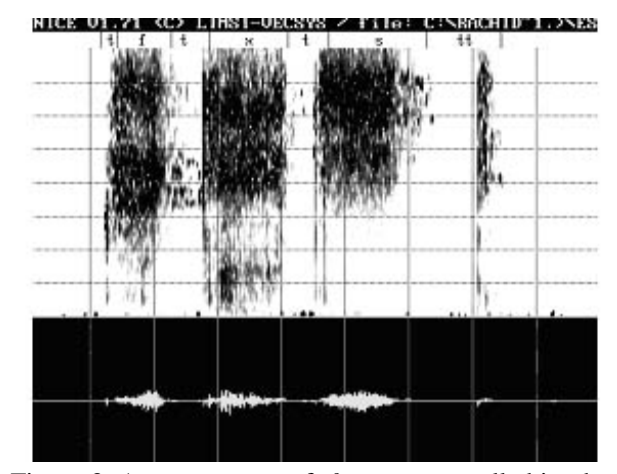

Figure 3. A spectrogram of $t f t \chi t s t t \ll$ you rolled it » by E.

An additional important observation is that schwas occur mainly in the Agadir sub-system subjects. Does this mean that the syllabic system of this variety is different from that of the other varieties? This question merits thinking about especially since Coleman (1996) is based on some data uttered by a subject belonging to this area. My own judgement as a native speaker of Haha variety, having lived for a long time in Agadir, prompts me to consider this variations to be mainly due to the influence of Moroccan Arabic (henceforth MA) pronunciation. It is a known fact that TB speakers raised in Agadir or in any other Arabic-

\footnotetext{
${ }^{6}$ We have translated these two sentences from French.

${ }^{7}$ Compare the case of this schwa with the schwa in the Ath Sidhar Berber dialect spoken in the North of Morocco which never occurs word-finally. In this dialect, an epenthetic schwa, unlike in TB, is inserted in order to syllabify consonants which would otherwise remain unsyllabified (see Dell and Tangi 1992)

${ }^{8}$ Personal communication of N. Clements.
} 
speaking city mimic the MA pronunciation considered to be more prestigious. ${ }^{9}$ Subject E, who lived in Agadir, may insert schwas to break up consonant clusters, but this is not acceptable for subject $\mathrm{K}$, for example, who lived in a remote Berber village for more than thirty years before coming to France. This phenomenon is illustrated by the form szef, which is a MA loan word totally integrated in the TB lexicon. Subject E mimicked the MA pronunciation of this form with a schwa that must be pronounced in MA before the last consonant when realized in isolation. Consider the spectrogram of this item as realized by subject $\mathrm{E}$ and compare it with the spectrogram of the same form realized by a MA native speaker: ${ }^{10}$

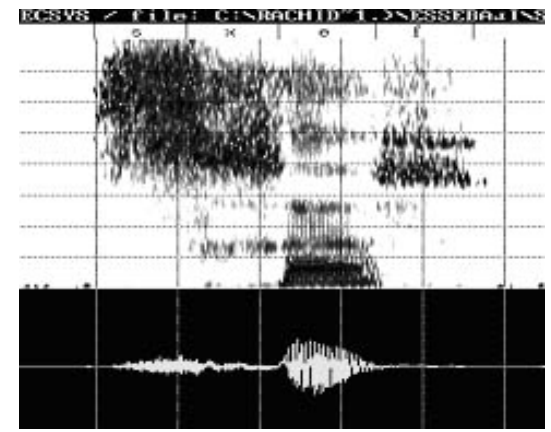

Figure 4. A spectrogram of sxef « fade away » by E.

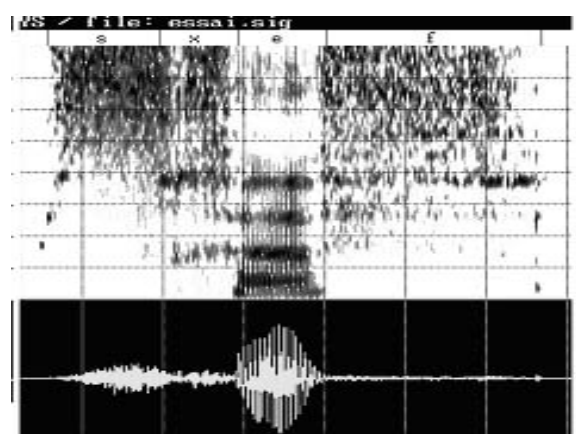

Figure 5. A spectrogram of sxef « fade away » by a MA native speaker.

One last observation concerns voiceless schwas. Coleman's and Louali and Puech's claims don't extend to these segments. None of our 7 subjects produces voiceless schwas. Our speakers either pronounce voiced schwas or no schwas at all. A voiceless schwa is a vowel with formants but which lacks the voicing bar. No such segment was detected through our spectrograms. The phonological argument which will be developed below also precludes the presence of this segment.

To summarize, the acoustic analysis allows us to argue for the absence of schwa vowels in voiceless obstruent sequences. But this is not without exceptions. What we have shown in this section is that these exceptions fall into two classes. The first class of exceptions concerns the presence of schwa vowels mainly in the final position of the utterance. The presence of schwa in the periphery is considered to be a cue to identify the final consonant by placing it in a prevocalic position. The second class of exceptions involves the internal schwas, whose presence is due to the influence of MA pronunciation.

\footnotetext{
${ }^{9}$ See Dell and Elmedlaoui (in press), who have observed MA like schwas in the speech of the Chleuhs living in an Arabic-speaking city. Giving several examples for illustration, they observed that the command of TB tends to deteriorate and that adaptations from the dominant language are increasingly resorted to.

${ }^{10}$ The two other forms containing a schwa at the internal position in $t f t h$ and sfqqst are all MA loan words. The other form with internal schwa $t f s s$ is a native TB verb that may be realized in two ways: $t f f i s$ with a full vowel or a vowel-less $t f s s$. These two realizations are in free variation.
} 


\section{$3 \quad$ Physiological arguments}

\subsection{Method}

While the configuration of the glottis for voiceless consonants - especially voiceless aspirated stops - in CV, VCV and VC are well accounted for, much work is still to be done for an understanding of laryngeal movements in more complex environments. TB, which allows long voiceless sequences, provides one of the most suitable fields for examining these laryngeal movements.

The most convenient source of information on laryngeal movements in obstruent sequences is a series of articles published by Löfqvist and colleagues. In these articles, sequences of voiceless sounds in American English, Dutch, Swedish, Icelandic and Japanese were studied. Concerning Berber, this paper is the first attempt to deal with such topic in this language.

One native speaker of Haha sub-variety of TB served as subject for this experiment, a 30-year-old male. ${ }^{11}$ The video-endoscopic experiment was performed by means of a flexible nasofibroptic laryngoscopy (Olympus ENF P3) with video recording (25 frames/s). ${ }^{12}$ A fiberscope was inserted through the nostril of the subject. A camera Sony (XC-999 P) was fixed on the external side of the fiberscope which enabled us to record a video film on a UMatic Sony tape recorder (VO-5800 PS). The internal side was stabilized a bit over the larynx which provided an immediate visualization of the dynamic behaviour of the laryngeal region. The laryngeal evaluation included the abduction and adduction movements of the vocal folds as well as inward and forward movements of the arytenoid cartilages. A synchronization signal was recorded on one channel of the tape recorder for frame identification. The film was analysed by means of a PC using the programs Adobe Premiere and Adobe Photoshop.

The corpus consisted of the same forms as for the spectrographic analysis (see (1) above). A supplementary data below was also recorded in order to have a view of the dynamic behaviour of the larynx during the production of some French and MA words. The aim is to compare the behaviour of the glottis during the production of French voiceless sequences (underlined sequences in (2) below) and MA words with the state of the glottis during the realization of TB items: ${ }^{13}$

(2) French items

$\begin{array}{ll}\text { aksstilo } & \text { "every pen" } \\ \text { feliksfoR } & \text { "Felix Faur" }\end{array}$

(3) MA Items
fse $\chi$
fqqes
"He cancelled"
"irritate"

Each item of (1), (2) and (3) was produced six times in isolation. The rest interval between consecutive items was approximately 2-3 seconds. Our data consists of 162 utterances.

\footnotetext{
${ }^{11}$ I served as a subject for this experiment. My wish was to have at least three subjects, each representing one variety of TB, but all the persons I contacted showed little motivation to take part in the experiment. This is certainly due to the nature of the experiment, which may seem somehow repugnant.

${ }^{12}$ These recordings were made at Laennec Hospital in Paris, with the cooperation of Doctor Lise Crevier.

${ }^{13}$ Notice that the sequence $\underline{k s t}$ in fakstilo is identical to the TB item kst "feed it on" and that fqqes exists also in TB but with no schwa vowel. This item originates from MA.
} 


\subsection{Results and discussion}

The difference between vowel-less obstruent sequences and sequences with a schwa vowel can be easily observed by means of video-endoscopy. The two figures below give an immediate visualisation of one state of the glottis during the production of a voiceless obstruent sequence (Figure 6) and one state of the glottis during the production of $f$ se $\chi$, a MA item having a schwa vowel before the final consonant (Figure 7).

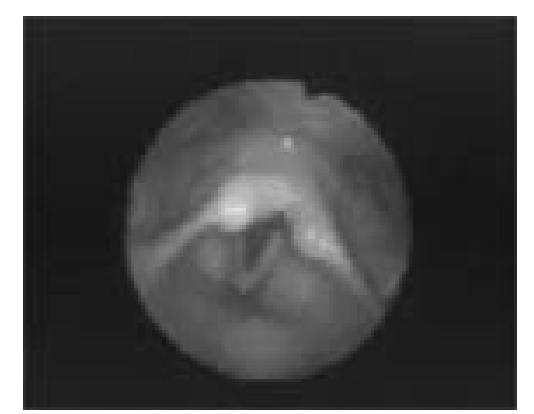

Figure 6. One state of the glottis for TB [tss $\underline{\boldsymbol{k}} \mathrm{ft}]]^{14}$

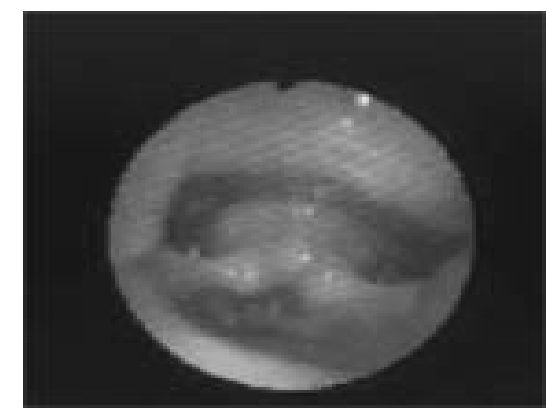

Figure 7. One state of the glottis for MA [fse $x]$.

We have observed very similar laryngeal movements during the production of items (1). At the initial position, the glottis is widely open. This configuration is identical to the one in Figure 6 above. As is shown in Figure 12 ${ }^{15}$, for the form $t f s$ t, for example, the state of the glottis for the closing (or onset) phase of the oral stop /t/, which corresponds to the first image, can be described as having an abducted glottis, abducted vocal folds and abducted arytenoid cartilages. The glottis maintains this quasi static position of opening during the period of the utterance of the whole cluster. This configuration of the glottis is the same for all the utterances of the 23 clusters of voiceless obstruents we have analysed, regardless of the number of consonants they have (see Figure 14 for tftktstt, a sequence of 8 voiceless obstruents). All these forms show an uninterrupted devoicing through the sequence. When the arytenoids are this far apart the vocal folds can not be set into vibration.

We have also observed a general tendency to lower the glottis towards the end of each statement. There is also a general tendency to bring the vocal folds closer, but still not adducted, at the end of each form. The arytenoid cartilages remain separated. This tendency is not due to the nature of the final consonants since it is attested after stops as well as after fricative segments as is shown in Figures 12 and 13. A parallel may be drawn between this observation and the fact that certain subjects may realize schwas at the end of the utterances. We might consider that this tendency may attend a further degree of glottal closing to reach a vocalization phase for certain subjects as is the case for $\mathrm{H}, \mathrm{E}, \mathrm{B}$ and $\mathrm{S}$.

As outlined above, we have examined some French voiceless sequences and compared them with TB items. This experiment was designed to investigate further evidences proving the absence of vowel gestures in TB voiceless sequences. Another purpose was to provide some more observations of the laryngeal movements in the two languages.

The French sequence /k\#st/ shows an interrupted devoicing through the sequence. The same observation showing separation of the vocal folds occurs in TB kst. Below, two states of

\footnotetext{
${ }^{14}$ If a single segment is underlined, as is the case in Figure 6, the image shows a frame corresponding to a medial portion of that segment, and if two segments are underlined, it shows a frame at the transition between the two.

${ }^{15}$ The Figures 12 to 19 are in the Index. The primes in these figures indicate the closing phase as in [' $t$ ] and the release phase as in [t'].
} 
the glottis during the production of the two sequences. Both images correspond to the onset phase of the final stop /t/ (see Figures 15 and 16 for a visualization of the whole sequences).

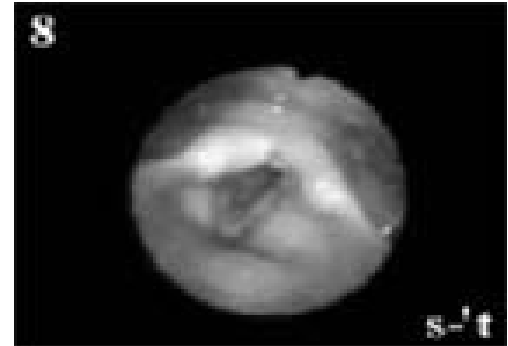

Figure 8. One state of the glottis during the production of TB [kst].

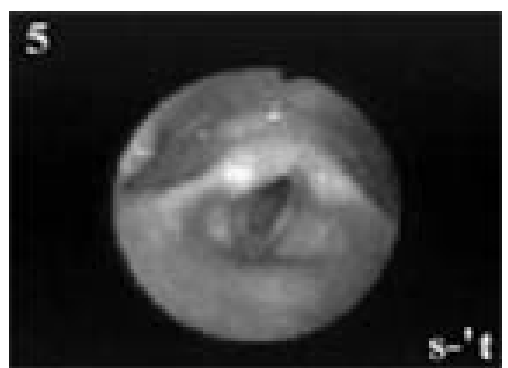

Figure 9. One state of the glottis during the production of French [Jakstilo].

Differences between the two sequences can be detected. Our observations show that the degree of glottal opening is not the same in the two forms. In TB kst the glottis opening is wide and maintains this degree through the whole sequence. ${ }^{16}$ In French $/ \mathrm{k}$ st/ however, the glottis is slightly open during the onset and the closure phases of the stop / $/$ / and opens gradually to reach its maximal width at the onset phase of the final /t/ then starts closing gradually.

As we have pointed out earlier, clusters of voiceless consonants provide one of the most suitable fields for examining the processes of coarticulation and coproduction at the laryngeal level by examining how the simple ballistic-looking pattern of abduction-adduction found in singular consonants followed by a vowel is modified when sequences of voiceless consonants occur. One important issue to examine is the relative extent of anticipatory effects.

In analysing sequences of voiceless obstruents followed by a vowel such as French /k\#st/ in Sakstilo, we have observed that the glottis moves gradually to a closing phase during the realization of the dental / $t /$ which is followed by a vowel. We believe that this an anticipating effect of the following vowel. The glottis seems to anticipate the closing gesture necessary for the realization of a vowel. We have observed the same phenomenon in TB sequences of voiceless obstruents followed by a vowel such as $t s k t i$ "she reminded" in Figure 19. ${ }^{17}$ As we shall see below, the same anticipating effect is observed in MA items as well.

So far different arguments have been developed showing the absence of vowel gestures in TB voiceless items. One last argument is provided by the comparison of the two realizations of the forms fqqs. As is outlined in the acoustic section, some TB items are MA loan words. fqqs is one such item. In MA, an epenthetic schwa is inserted before the last consonant. Such vowel does not exist in TB. Figure10 below shows a clear vowel gesture and thus voicing after the occlusion of the geminate stop /qq/ in the MA fqqes. Whereas in Figure 11 , no such vocalic gesture is attested either in this position or elsewhere in the sequence (see Figures 17 and 18 in the Index for the whole sequences of the two forms).

\footnotetext{
${ }^{16}$ The observation deduced from this material suggests a slightly different picture from the observations of Löfqvist and Yoshioka (1980) who argued that: "There is little, if any evidence that the glottis ever opens and maintains a static position in speech."

${ }^{17}$ The fact that the glottis anticipates the realization of the following vowel is more obvious when we compare the final /t/ in the two Figures 14 and 19.
} 


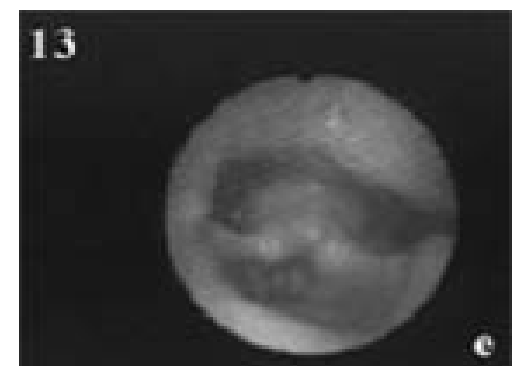

Figure 10. One state of the glottis during the production of MA [fqqes].

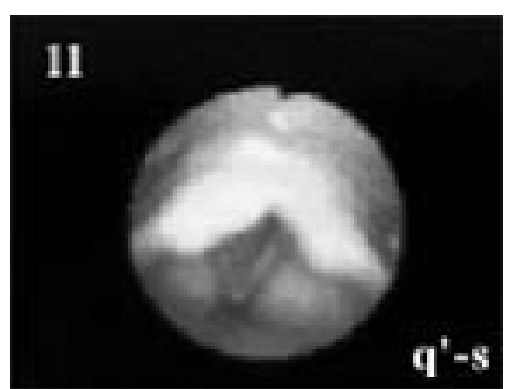

Figure 11. One state of the glottis during the production of TB [fqqs].

The anticipatory effect observed in French and TB items is also attested in MA. In fact, after the maximal opening of the glottis maintained from the beginning of the utterance until the onset phase of the geminate /qq/, the glottis closes gradually to reach a maximal closing after the occlusion of the stop.

In French $/ \mathrm{k \# st/,} \mathrm{the} \mathrm{velar} \mathrm{stop} \mathrm{is} \mathrm{preceded} \mathrm{by} \mathrm{a} \mathrm{vowel} \mathrm{as} \mathrm{in} \mathrm{\int akstilo.} \mathrm{In} \mathrm{the} \mathrm{MA} \mathrm{item}$ fqqes, the fricative /s/ is also preceded by a vowel. The laryngeal movements are not the same for the two segments. In MA, we observed that the onset of glottal opening is very early with a maximal opening immediately after the vowel (see Figure 18). In French, the opening is rather slow and the glottis opens gradually before reaching a maximal opening after at the onset phase of the final $/ \mathrm{t} /$. One possible reason for these differences is due to the nature of the two consonants following the vowel: a stop $/ \mathrm{k} /$ in the French item and a fricative $/ \mathrm{s} /$ in MA. ${ }^{18}$ In fact, there is a fairly widespread finding in literature that abduction is more rigorous in fricatives than in stops. Our observations are consistent with the observations of Löfqvist and Yoshioka (1980) and Yoshioka et al. (1981) using respectively Swedish and American English as well as with other literature findings ${ }^{19}$. Löfqvist and McGarr (1987: 399) (cited in Hoole 1997) discuss reasons for the larger glottal gestures in fricatives: "The larger gesture for a voiceless fricative is most likely due to the aerodynamics of fricative production, in that a large glottal opening not only prevents voicing but also reduces laryngeal resistance to air flow and assists in the build up of oral pressure necessary for driving the noise source."

To summarize, our physiological observations show the absence of vocalic gestures in all the utterances of the 23 forms analysed. All these forms show separation of the vocal folds and the arytenoid cartilages. Just as there are no vowel gestures in French voiceless sequences, so is the case in TB. The particular laryngeal configuration in French sequences is believed to be mainly due to anticipatory effects. The comparison with MA items shows a clear difference between a sequence having a schwa vowel and a sequence deprived of any vocalic gesture. Various observations either in accord or in disaccord with some literature findings are also deduced. These observations will be dealt with in some detail in forthcoming studies.

\section{$4 \quad$ Phonological argumentation}

The phonological analysis is based on the behaviour of vowels with respect to the phonological rule of assibilation according to which the dental stops $/ \mathrm{t} /$ and $/ \mathrm{d} / \mathrm{become} / \mathrm{s} /$ and /z/ respectively. The dental stops maintain their occlusion when they are immediately in contact with a coronal consonant e.g. /itri/ $\rightarrow$ itri "star". When the dentals are separated from the coronals by one of the vowels /a, i, or $\mathrm{u} /$, the process of assibilation operates e.g. /tura/ $\rightarrow$ sura "she wrote". The aim of the phonological analysis is to check the behaviour of dental

\footnotetext{
${ }^{18}$ The maximal glottal opening tends to coincide with the location of [s] in French as well (see Figure 16).

${ }^{19}$ See Hoole (1997) for a summary of this literature and the references therein.
} 
stops when separated from other coronal consonants, according to certain analyses and transcriptions, by the vowel [e]. Our analysis is based on the data analysed by Louali-Raynal (1999). We have chosen this data on purpose so as to compare easily her conclusions with the conclusions the same author published in another work (Louali and Puech 1999b) on syllabification in the same variety of TB.

A general claim is that schwa is invisible in regard to all relevant phonological processes and constraints in TB. For example, it is invisible in regard to assibilation. Assibilation is a phonological process attested in the Anti-Atlas variety whereby dentals / $/$ / and /d/ are realized as sibilants $[\mathrm{s}]$ and $[\mathrm{z}]$ respectively:

$\begin{array}{lll}\text { /tifawt/ } & \text { sifaws } & \text { light } \\ \text { /tabawt/ } & \text { sabaws } & \text { bean } \\ \text { /tafukt/ } & \text { safuks } & \text { honey } \\ \text { /tilkit/ } & \text { silkis } & \text { louse } \\ \text { /tirgit/ } & \text { sirgis } & \text { embers } \\ \text { /tismegt/ } & \text { sismegs } & \text { slave }\end{array}$

The dentals maintain their occlusion when they are in contact with another coronal segment:

$\begin{array}{lll}\text { /adrar/ } & \text { adrar } & \text { mountain } \\ \text { /itri/ } & \text { itri } & \text { star }\end{array}$

The maintain of occlusion does not operate across the vowels /a, i, u/:

\begin{tabular}{|c|c|c|}
\hline & sura & she wrote \\
\hline /idurar/ & izurar & mountains \\
\hline /issuda/ & issuza & she rode \\
\hline /tarwa/ & sarwa & children \\
\hline /tiryi/ & siryi & heat \\
\hline
\end{tabular}

Louali-Raynal (1999) provided the verb below for illustration. This form according to her transcription contains a schwa vowel ${ }^{20}$ :

terkez she wore

Let us suppose that this vowel exists and that /trkz/ contains a schwa between the coronal clusters $/ \mathrm{t} / \mathrm{and} / \mathrm{r} /$. The schwa here should normally make assibilation possible since $/ \mathrm{t} / \mathrm{and} / \mathrm{r} /$ are not adjacent. If assibilation took place in (7), it would be pronounced in a way that should be represented as serkez in the transcription of Louali-Raynal. But this is not the case, the dental / $t /$ maintains its occlusion. If we admit the presence of a vowel [e] in this form, we should then explain why vowels /a, i, u/ don't obstruct assibilation as in (6) while the vowel [e] does. This problem does not appear in our analysis in which [e] is not a segment of TB. ${ }^{21}$

The comparison with some Berber dialects which contain a vowel [e] is very instructive. The Beni Iznassen Berber dialect spoken in the North of Morocco spirantizes the

\footnotetext{
${ }^{20}$ In many works on Tashlhiyt and not only in Loauli-Raynal (1999), consonant clusters in this environment are as a rule separated by a schwa.

${ }^{21}$ The argumentation developed here concerning assibilation is analogous in its principle to that of F. Dell and M. Elmedloui (2000). Their argumentation makes use of regressive devoicing.
} 
dental $/ \mathrm{t} /$ except when preceded immediately by $/ \mathrm{m} /{ }^{22}$ as is shown by the data below (from $\mathrm{El}$ Kirat 1987: 216):

$$
\begin{aligned}
& \text { Eandamt regret } \\
& \theta \text { †imt ditrict }
\end{aligned}
$$

When the schwa separates the labial $/ \mathrm{m} /$ from the dental, spirantization takes place:

$$
\begin{aligned}
& \text { lxeðme } \theta \quad \text { work }
\end{aligned}
$$

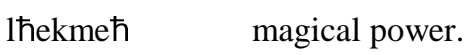

Unlike in TB, the surface representations of Beni Iznassen Berber contain a vowel [e] which, by separating the dental / $\mathrm{t} /$ from the labial $/ \mathrm{m} /$, makes spirantization possible ${ }^{23}$.

\section{Conclusion}

The different arguments we have developed so far prove that schwa is not a segment at the level of phonetic representations in TB. The acoustic arguments showed the predominance of realizations of long sequences of voiceless obstruents with no schwa vowel. The presence of this vowel in the final position of some utterances is believed to be a cue used for the hearer to identify the final consonants by placing them in a prevocalic position. Its presence in the internal position is due to the influence of MA. The physiological arguments exclude the presence of vocalic gestures in these sequences, where the vocal folds and the arytenoid cartilages remain widely separated and the glottis clearly open. The possibility of the presence of a voiceless schwa is excluded by our phonological analysis. No vowel, be it voiceless, separates dentals and coronals in our data. This paper shows that many TB words lack phonological or phonetic vowels. Since no vowel exists in the forms similar to (1), any consonant may then occupy the position of a syllable nucleus, even a voiceless stop. Relying on these conclusions, we are conducting a study to determine if the syllabic consonants have some phonetic properties that differentiate them from their non syllabic counterparts.

\footnotetext{
${ }^{22}$ Spiratization is inhibited as well when preceded by /l, $\mathrm{n} /$.

${ }^{23}$ The argumentation developed here does not take into account a possible rule of schwa epenthesis which, if it exists, may follow and thus counterfeed the rule of assibilation. On the absence of schwa epenthesis in TB, see Dell and Elmedlaoui (1996).
} 


\section{References}

Benguerel, A. \& Bhata, T. (1980), "Hindi stop consonants: an acoustical and fiberscopic study", Phonetica 37, pp. 134-148.

Boukous, M. (1990), “Vocalité, sonorité et syllabicité”, Awal, nº spécial: Hommage à Mouloud Mammeri, pp. 203218.

Boukous, M. (1994), “Variation phonique et Compétence globale: le cas du parler d'Agadir ”, Publications de la Faculté des Lettres. Rabat.

Clements, N. (1997), "Berber syllabification: Derivations or Constraints ?”, in Derivations and Constraints in Phonology, Iggy Roca eds., Clarendon Press, Oxford, pp. 289-330.

Coleman, J. (1996), "Declarative Syllabification in Tashlhiyt Berber", in: Current trends in phonology, J. Durand \& B. Laks (eds), CNRS, Paris X \& University of Salford, University of Salford Publications, pp. 175-216.

Coleman, J. (1999), "The nature of vocoids associated with syllabic consonants in Tashlhiyt Berber", Proceedings of the $14^{\text {th }}$ International Congress of Phonetic Sciences, San Fransisco, 1-7 August 1999, pp. 735-738;

Dell, F. \& Elmedlaoui, M. (1985), "Syllabic Consonants and Syllabification in Imdlawn Tashlhiyt Berber", Journal of African Languages and Linguistics 7, pp. 105-130.

Dell, F. \& Elmedlaoui, M. (1988), "Syllabic consonants in Berber: Some new evidence”, Journal of African Languages and Linguistics 10, pp. 1-17.

Dell, F. \& Elmedlaoui, M. (1996), "Nonsyllabic transitional vocoids in Imdlawn Tashlhiyt Berber", in: Current trends in phonology, J. Durand \& B. Laks (eds), CNRS, Paris X \& University of Salford, University of Salford Publications, pp. 217-244.

Dell, F. \& Elmedlaoui, M. (1997), "La syllabation et les géminées dans la poésie berbère du Maroc (dialecte chleuh)", in: Cahiers de Grammaire $\mathrm{N}^{\circ} 22$, pp. 1-95.

Dell, F. \& Elmedlaoui, M. (2000), "Syllabification in Moroccan Arabic and how it differs from that in Tashlhiyt Berber", Proceedings of the $5^{\text {th }}$ International Conference on Afroasiatic Languages, Paris, June 28-30.

Dell, F. \& Elmedlaoui, M. Syllables in Tashlhiyt Berber and in Moroccan Arabic. In press.

Dell, F. \& Tangi, O. (1993), "Syllabification and Empty nuclei in Ath-Sidhar Rifain Berber", Journal of African Languages and Linguistics 13, pp. 125-162.

El Kirat, Y. (1987), Spirantization in the Beni Iznassen dialect, diachrony and synchrony. Unpublished thesis of D.E.S, Mohammed V University, Rabat.

Elmedlaoui, M. (1985), Le parler berbère chleuh d'Imdlawn (Maroc); segments et syllabation. Unpublished thèse de Troisième cycle, Université de Paris VIII.

Kagaya, R. (1974), "A fiberscopic and acoustic study of the Korean stops, affricates and Fricatives”, Journal of Phonetics 2, pp. 161-180.

Löfqvist, A. \& Yoshioka, H. (1980), "Laryngeal activity in Swedish Obstruent clusters," The Journal of the Acoustical Society of America, 68, pp. 792-801.

Louali-Raynal, N. (1999) “La spirantisation en berbère” Afroasiatica Tergestina Papers from the $9^{\text {th }}$ Italian Meeting of Afro-Asiatic (Hamito-semitic) Linguistics, Treiste, 23-24 April 1988, Unipress, pp. 271-298.

Louali, N. \& Puech, G. (1996), "Syllabic consonants in Tashlhiyt Berber : the case of unvoiced stops", Communication about : The phonology of the World's Languages : The Syllable, Pezenas, 21 au 24 juin.

Louali, N. \& Puech, G. (1999 a), "Syllabification in Berber, the case of Tashlhiyt", Proceedings of the $14^{\text {th }}$ International Congress of Phonetic Sciences, San Fransisco, 1-7 August 1999, pp. 747-750.

Louali, N. \& Puech, G. (1999 b), “La syllabe en berbère Tachelhit”, in Syllabes: IIèmes Journées d'Etudes Linguistiques, Université de Nanterre, S.Wauquier - Gravelines et S. Ferré, eds.

Harris, G. H. (1999), "States of the glottis for Voiceless Plosives", Proceedings of the $14^{\text {th }}$ International Congress of Phonetic Sciences, San Fransisco, 1-7 August 1999, pp. 2041-2044.

Hoole, P. (1997), "Laryngeal coarticulation : coarticulatory investigations of the devoicing gesture", Forschungsberichte des Instituts für Phonetik und Sprachliche Kommunikation der Universität München (FIPKM) 35, pp. 89-99.

Yoshioka, H., Löfqvist, A. \& Hirose, H. (1981), "Laryngeal adjustments in the production of consonant clusters and geminates in American English”, The Journal of the Acoustical Society of America, 70, pp. 1615-1623. 